\title{
Prevalence, severity and etiology of dental wear in patients with eating disorders
}

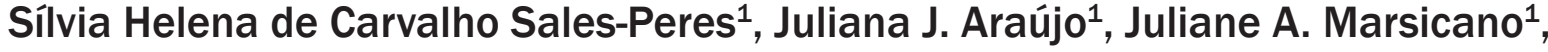 \\ José E. Santos ${ }^{2}$, José R. M. Bastos ${ }^{1}$
}

Correspondence: Dr. Sílvia Helena de Carvalho Sales-Peres

'Department of Pediatric Dentistry, Orthodontics and Public Health, Bauru School of Dentistry, University of São Paulo, Al. Octávio Pinheiro Brisolla, 9-75, Bauru-SP 17012-901, Brazil,

${ }^{2}$ Department of Medical Clinic, Faculty of Medicine of Ribeirão Preto, University of São Paulo, Avenida Email: shcperes@usp.br Bandeirantes, 3900, Ribeirão Preto, SP, Brazil

\section{ABSTRACT}

Objective: The purpose of this study was to evaluate the prevalence, distribution and associated factors of dental wear among patients with eating disorders (EDs). Materials and Methods: An epidemiological cross-sectional survey was conducted by trained, calibrated examiners, using the dental wear index. The sample was composed of 30 patients with EDs (experimental group - G1) and 30 control patients without current or previous history of EDs (G2). A questionnaire was used to assess the etiological factors of dental wear. The univariate analyses using the Chi-square $\left(\chi^{2}\right)$ test were used to compare the tooth wear prevalence between groups according to the surface and tooth $(P>0.05)$. Results: The dental wear was similar for both group; however, the G1 presented more moderate wear in molars when compared with G2 $(P=0.048)$. The majority of EDs patients related have one or more oral habits $(n=26 ; 86.6 \%)$ and only $13.4 \%(n=4)$ affirmed did not have oral habits. The etiological factors of tooth wear related with dental wear were biting objects $(P=0.04)$ and pain in temporomandibular disorders $(P=0.03)$. Conclusion: The highest prevalence of dental wear was observed in the molars teeth. Differences in the extent and pattern of dental wear were found in an individual, emphasized the relevance of clinical parameter.

Key words: Anorexic, bulimic, eating disorders, oral health, tooth wear

\section{INTRODUCTION}

Eating disorders (EDs) are relatively rare among the general population and patients tend to deny or conceal their illness and avoid professional help. ${ }^{[1]}$ EDs are psychiatric illnesses associated with serious physical and psychosocial morbidity and significant mortality. ${ }^{[2]}$ The main EDs are anorexia nervosa and bulimia. EDs have increased in magnitude, incidence and prevalence that cause a concern to health-care professionals. The prevalence of bulimia in the general population is low, but together with anorexia nervosa it is among the most serious diseases affecting young women. ${ }^{[3]}$ EDs can actually lead to metabolic, morphological and functional alterations of multiple organs and systems, exhibiting varying degrees of morbidity and sometimes resulting in life-threatening outcomes. ${ }^{[4]}$ The anorexia is a disturbed body image that the patient has a morbid fear of weight gain despite underweight status and refusal to maintain a minimally normal body weight. ${ }^{[2]}$ The bulimia is a binge eating that is followed by inappropriate compensatory behavior to prevent the weight gain as misuse of laxatives, self-induced vomiting and others. ${ }^{[2]}$ Bulimia and anorexia can be associated with many complications including the ones within the oral cavity. ${ }^{[5]}$

Persistent vomiting leads to severe reflux of gastric acid that may extend from the stomach to the oropharynx.

\footnotetext{
How to cite this article: de Carvalho Sales-Peres SH, Araújo JJ, Marsicano JA, Santos JE, Bastos JR. Prevalence, severity and etiology of dental wear in patients with eating disorders. Eur J Dent 2014;8:68-73.

Copyright $\odot 2014$ Dental Investigations Society. DOI: $10.4103 / 1305-7456.126246$
} 
This may lead to dysphagia and heartburn. Gastric acid is an irritant to the vocal cords and over years may also lead to hoarseness. ${ }^{[6]}$ EDs in combination with vomiting (bulimia nervosa) are at high risk for often associated with regurgitation of gastric contents into the mouth and dental erosion. ${ }^{[7,8]}$ Dental complications due to eroding effects of repeated self-induced vomiting are objective signs of bulimia. ${ }^{[9,10]}$ This suggests that other parameters than the duration of ED may contribute to severity and progression of dental erosions seen in persons with bulimia. The oral manifestation of EDs were mucosal lesions, periodontal lesion and salivary manifestations. ${ }^{[4]}$

The oral manifestations can interfere with pathogenetic factors of EDs, thus influencing disease behavior and management. Tooth wear may have physical (abrasion and attrition) and/or chemical (erosion) origin. Bulimics patients have shown significantly higher dental erosion. ${ }^{[7,11,12]}$ Dental erosion is the progressive irreversible loss of dental hard tissue that is chemically etched away from the tooth surface by extrinsic and/or intrinsic acids and/or chelation by a process that does not involve bacteria. Intrinsic acids are from vomiting and regurgitation. ${ }^{[13]}$ Dental erosion generally works synergistically with abrasion and attrition to cause loss of tooth structure, making diagnosis and management complex. ${ }^{[14]}$

The clinical signs of dental erosion are initially subtle; yet they often progress because the patient remains asymptomatic, unaware and uninformed. Dental wear diseases have a considerable impact on self-esteem and on quality-of-life. ${ }^{[13]}$ Awareness of this disease is not well-appreciated by the public and dental professionals because the signs may be subtle and thus, the purpose of the cure. Bulimics patients have been significantly higher dental erosion not study was to investigate prevalence, severity and etiology of dental wear in a group of EDs patients.

\section{MATERIALS AND METHODS}

\section{Ethical aspects}

The study was approved by the Research Ethics Committee of the Ribeirão Preto Medicine Hospital, University of São Paulo (Protocol \# 28.32/2007). Written permission from patients was obtained before starting the clinical examinations.

\section{Study design}

The selected patients, for this study were diagnosed with bulimia or anorexia according to the diagnostic of mental disorders criteria ${ }^{[15]}$ and they were being treated in the Group of Assistance to the EDs, Hospital of Ribeirão Preto Medicine College, University of São Paulo. Assistance group is composed of professionals of nutrition, medics, physiatrists, psychologies and dentist for attending the EDs patients in the Hospital of Ribeirão Preto Medicine School. The control group was composed of healthy individuals and was recruited at Hospital of Ribeirão Preto.

The sample of this study was composed of 60 participants being experimental group $(\mathrm{G} 1=30)$ and control group $(\mathrm{G} 2=30)$, with 5 males and 55 females. The mean age was 26.8 years old. The experimental group was divided into anorexia nervosa $(n=17)$, bulimia nervosa $(n=12)$, compulsive $\operatorname{ED}(n=1)$.

\section{Calibration}

The examiner was performed theoretical and practical activities with discussions on diagnosis criteria of dental wear-dental wear index (DWI) conducting by a gold standard examiner. ${ }^{[16]}$ Approximately, $10 \%$ of the sample was re-examined in order to verify the intra-examiner reproducibility. The Kappa score for intra-examiner agreement was $0.90(93.75 \%)$ expressed. This value indicated reliability within excellent concordance. ${ }^{[17]}$

\section{Examination methodology}

Clinical examination was performed by one previously calibrated examiner, under artificial light, using CPI probes ("ball point"), mirrors $\# 5^{[18]}$ and air-drying. All patients before the exam realized a tooth brushing supervised.

Inclusion criteria were to consent in participates of the research, to be fully dentate and do not have any tooth mobility. Teeth were excluded if they were missing, had extensive caries, large restorations, fractures or bonded orthodontic brackets.

\section{Diagnostic criteria and codes}

The DWI ${ }^{[16]}$ was used to evaluate dental wear. The criteria used for examination employed numbers for permanent teeth, respectively: 0 - Normal (no evidence of wear); 1 - Incipient (tooth wear in enamel); 2 - Moderate (tooth wear in dentin); 3 - Severe (tooth wear in pulp or secondary dentin); 4 - Restored (tooth wear leading to restoration); 9-Could (not be assessed). The occlusal/incisal, buccal and lingual/ palatal surfaces of all teeth present in the mouth were scored for tooth wear. ${ }^{[16]}$

\section{Questionnaire}

All patients received a semi-structured questionnaire to provide information that might 
be related to the type of lesion present in the teeth. The questionnaire was developed in relation to the main etiological factors of tooth wear, previously published in the literature. ${ }^{[19,20]}$ The amount and frequency of consumption of acidic products were included. The questionnaire covered details on medical history including gastroesophageal reflux, frequent vomiting and dry mouth. Finally, parafunctional habits such as tooth clenching or grinding, tongue biting, lip biting, gum chewing, cheek biting, objects biting or nail biting were assessed.

\section{Statistical analysis}

Data were entered into a personal computer using Statistica 7. For categorical variables, frequencies, percentages and distribution were calculated. The influence of independent variables (gastric disorders, dietary habits - consumption of acidic drinks, oral hygiene practices and parafunctional habits) on tooth wear was analyzed by univariate analyses using the Chi-square test at the $5 \%$ significance level.

\section{RESULTS}

Tables 1 and 2 show that the tooth wears was similar between the groups; however, the G1 present highest severity. This difference was statistically significant in molars $(P=0.048)$ [Table 3].

The majority of EDs patients related have one or more oral habits $(n=26 ; 86.6 \%)$ and only $13.4 \%(n=4)$ of them affirmed do not have oral habits. The tooth wear was correlated with dental wear were biting objects $(P=0.04)$ and pain in temporomandibular disorders-temporomandibular joints $(\mathrm{TMJ})(P=0.03)$ [Table 4$]$.

\section{DISCUSSION}

Anorexia and bulimia nervosa are diseases characterized by perturbed eating behavior patterns, a pathological control of body weight and disturbance in the perception of the body shape and these diseases cause systemic and oral alterations. Patients suffering

\begin{tabular}{|c|c|c|c|c|c|c|c|c|c|c|c|c|}
\hline \multirow[t]{4}{*}{ Surfaces } & \multicolumn{12}{|c|}{ Groups } \\
\hline & \multicolumn{4}{|c|}{ Buccal } & \multicolumn{4}{|c|}{ Oclusal/incisal } & \multicolumn{4}{|c|}{ Lingual/palatina } \\
\hline & \multicolumn{2}{|c|}{ EDG } & \multicolumn{2}{|c|}{ CG } & \multicolumn{2}{|c|}{ EDG } & \multicolumn{2}{|c|}{ CG } & \multicolumn{2}{|c|}{ EDG } & \multicolumn{2}{|c|}{ CG } \\
\hline & $n$ & $\%$ & $n$ & $\%$ & $n$ & $\%$ & $n$ & $\%$ & $n$ & $\%$ & $n$ & $\%$ \\
\hline \multicolumn{13}{|l|}{ Severity } \\
\hline \multicolumn{13}{|l|}{ Degree } \\
\hline 0 & 20 & -66.67 & 10 & -33.33 & 0 & 0 & 0 & 0 & 24 & -80 & 16 & -53.33 \\
\hline 1 & 2 & -6.67 & 12 & -40 & 6 & -20 & 10 & -33.33 & 0 & 0 & 10 & -33.33 \\
\hline 2 & 1 & -3.33 & 2 & -6.67 & 20 & -66.67 & 16 & -53.33 & 1 & -3.33 & 1 & -3.33 \\
\hline 3 & 0 & 0 & 0 & 0 & 0 & 0 & 0 & 0 & 1 & -3.33 & 0 & 0 \\
\hline 4 & 7 & -23.33 & 6 & -20 & 4 & -13.33 & 4 & -13.33 & 4 & -13.33 & 3 & -10 \\
\hline \multicolumn{13}{|l|}{ Prevalence } \\
\hline Yes & 10 & -33.33 & 20 & -66.67 & 30 & -100 & 30 & -100 & 6 & -20 & 14 & -46.67 \\
\hline No & 20 & -66.67 & 10 & -33.33 & 0 & 0 & 0 & 0 & 24 & -80 & 16 & -53.33 \\
\hline
\end{tabular}

\begin{tabular}{|c|c|c|c|c|c|c|c|c|}
\hline \multirow[t]{2}{*}{ Group of teeth } & \multicolumn{2}{|c|}{ Incisors $n(\%)$} & \multicolumn{2}{|c|}{ Canines $n(\%)$} & \multicolumn{2}{|c|}{ Premolars $n(\%)$} & \multicolumn{2}{|c|}{ Molars $n(\%)$} \\
\hline & EDG & CG & EDG & CG & EDG & CG & EDG & GC \\
\hline \multicolumn{9}{|l|}{ Severity } \\
\hline \multicolumn{9}{|l|}{ Degree } \\
\hline 0 & $6(20.0)$ & $2(6.7)$ & $3(10.0)$ & $1(3.3)$ & $9(30.0)$ & $0(0.0)$ & $3(10.0)$ & $0(0.0)$ \\
\hline 1 & $2(6.7)$ & $9(30.0)$ & $6(20.0)$ & $12(40.0)$ & $12(40.0)$ & $22(73.4)$ & $16(53.3)$ & $25(83.4)$ \\
\hline 2 & $10(33.3)$ & $10(33.3)$ & $21(70.0)$ & $17(56.7)$ & $9(30.0)$ & $7(23.3)$ & $11(36.7)$ & $4(13.3)$ \\
\hline 3 & $6(20.0)$ & 7 (23.3) & $0(0.0)$ & $0(0.0)$ & $0(0.0)$ & $0(0.0)$ & $0(0.0)$ & $0(0.0)$ \\
\hline 4 & $6(20.0)$ & $2(6.7)$ & $0(0.0)$ & $0(0.0)$ & $0(0.0)$ & $1(3.3)$ & $0(0.0)$ & $1(3.3)$ \\
\hline \multicolumn{9}{|l|}{ Prevalence } \\
\hline Yes & $24(80.0)$ & $28(93.3)$ & $27(90.0)$ & $29(96.7)$ & $21(70.0)$ & $30(100.0)$ & $27(90.0)$ & $30(100.0)$ \\
\hline No & $6(20.0)$ & $2(6.7)$ & $3(10.0)$ & $1(3.3)$ & $9(30.0)$ & $0(0.0)$ & $3(0.0)$ & $0(0.0)$ \\
\hline
\end{tabular}




\begin{tabular}{|c|c|c|c|c|c|c|}
\hline \multirow[t]{2}{*}{ Groups } & \multirow[t]{2}{*}{$N$} & \multicolumn{3}{|c|}{ Degree $n(\%)(\mathrm{Cl} 95 \%)$} & \multirow[t]{2}{*}{$x^{2}$} & \multirow[t]{2}{*}{$P$} \\
\hline & & 0 & 1 & 2 & & \\
\hline Experimental & 30 & $0(0.00)$ & $6(20.00)$ & $24(80.00)$ & 1.3636 & 0.243 \\
\hline Control & 30 & $0(0.00)$ & $10(33.33)$ & $20(66.67)$ & & \\
\hline Total & 60 & & & & & \\
\hline
\end{tabular}

\begin{tabular}{|c|c|c|c|c|c|}
\hline \multirow[t]{2}{*}{ Factors } & \multicolumn{2}{|c|}{ Groups } & \multicolumn{3}{|c|}{ Univariate analysis } \\
\hline & TAS & GC & Odds ratio & $95 \% \mathrm{Cl}$ & $P$ value \\
\hline \multicolumn{6}{|l|}{ Buccal } \\
\hline Enamel & 2 & 12 & 0.1667 & $0.03-1.00$ & 0.092 \\
\hline Dentine & 8 & 8 & & & \\
\hline \multicolumn{6}{|l|}{ Oclusal } \\
\hline Enamel & 6 & 10 & 0.5000 & $0.15-1.61$ & 0.381 \\
\hline Dentine & 24 & 20 & & & \\
\hline \multicolumn{6}{|c|}{ Lingual/palatal } \\
\hline Enamel & 0 & 10 & - & - & $0.015^{\star}$ \\
\hline Dentine & 6 & 4 & & & \\
\hline \multicolumn{6}{|l|}{ Incisor } \\
\hline Enamel & 2 & 9 & 0.192 & $0.04-1.00$ & 0.079 \\
\hline Dentine & 22 & 19 & & & \\
\hline \multicolumn{6}{|l|}{ Canines } \\
\hline Enamel & 6 & 12 & 0.603 & $0.18-2.01$ & 0.600 \\
\hline Dentine & 21 & 17 & & & \\
\hline \multicolumn{6}{|l|}{ Premolars } \\
\hline Enamel & 12 & 22 & 0.485 & $0.15-1.58$ & 0.365 \\
\hline Dentine & 9 & 8 & & & \\
\hline \multicolumn{6}{|l|}{ Molars } \\
\hline Enamel & 16 & 25 & 0.291 & $0.08-0.99$ & 0.084 \\
\hline Dentine & 11 & 5 & & & \\
\hline
\end{tabular}

Cl: Confidence interval, EDG: Eating disorders group, CG: Control group. *Statistically significant difference $(P<0.05)$

from an ED in combination with vomiting (bulimia nervosa) are at high risk for dental erosion. ${ }^{[8]}$ Early detection of dental wear related with EDs may reduce the oral health risks and improve the likelihood that the patient would achieve long-term recovery these disorders. ${ }^{[2]}$ In this scenario, the knowledge about the prevalence of bulimia and anorexia nervosa and the relation with dental wear is important for health prevention and treatment of this patient.

If the progression of tooth erosion is to be interrupted in an initial stage, early diagnosis is essential. ${ }^{[21]}$ In a recent study, ${ }^{[22]}$ the accuracy of the visual diagnosis "dentin exposed" was found to be poor. Hence, the validity of currently used indices is not fully established. The DWI was proposed by Sales-Peres et al. $(2008)^{[16]}$ to improve the accuracy and reproducibility of the visual diagnosis the tooth wear in epidemiological surveys.
DWI was used in the present study and accuracy was excellent concordance (Kappa $=0.90) \cdot{ }^{[16]}$ Concerning the difficulty to identify the correctly exposure of dentine, as well as the possibly of exposed dentine even in cases of substance loss minor, the criterion enamel/dentine/pulp or secondary dentine was used in this study. Further studies about the indices adopted for dental wear should be discussed more.

In this study, the sample was not random from the general population but patients specifically referred to the clinic for investigation of tooth wear. During the sample selection, the inclusion criteria were patients attending for health professionals group at Ribeirão Preto Hospital. Thus, this study was composed of 60 female patients $(91.67 \%)$.

The EDs patients showed a higher severity of dentin erosion mainly in molars group of tooth. However, they did not show higher prevalence than the control group. This fact shows that all individuals are exposed to different types of dental wear and the experimental group had more severe erosive wear.

Dental wear can be caused by erosion, abrasion, attrition or abfraction. Erosion lesion may result from various factors, including intrinsic etiologies. The similarities among the intrinsic types of lesions and those caused by non-carious destructive mechanisms in the oral cavity may lead to conflict over their etiologies; as a result, these lesions may be ignored, undiagnosed, or misdiagnosed. The many systemic etiologies that propel stomach acid into the oral cavity, thereby causing dental erosion. ${ }^{[23]}$

Self-induced vomiting is the method most used by anorexic and bulimic patients to prevent them from gaining weight and is a destructive process that affects the hard dental tissues in the oral cavity. Patients with bulimia nervosa and anorexia nervosa of the purgative subtype present a classic erosion of the lingual surfaces of maxillary teeth. In this study, tooth erosion was predominantly found on palatal surfaces of upper anterior teeth and on occlusal surfaces of lower molars. This is in agreement with the findings of Jaeggi and Lussi (2006). ${ }^{[23]}$

Owing to the oral/systemic nature of EDs, this serious health issue requires comprehensive patient assessment and coordinated health treatment. Oral manifestations of EDs may appear in different stages along disease progression and thus exhibit a number of implications in assessment, characterization and management of this group of disorders. ${ }^{[2,25]}$ 
Lo Russo et al. (2008) ${ }^{[4]}$ reported that some oral manifestations may occur early during disease onset, therefore, identification/diagnosis can be very useful in early detection and adequate referral for prompt recovery.

In this scenario, the oral disease as dental sensitivity, dental erosion, oral pain and unusual oral sensations were reported for these patients. Some oral lesions may also help in defining the patient behavioral model, especially where dental erosion is very suggestive of vomiting induction. Patients with vomiting often presented 2.6 times more chance to have dental erosion than patients who had no vomiting, though the difference was not significant $(P>0.05)$. The etiological factors associated with dental wear were pain in TMJ and biting objects.

Another point to be considering is the administration of therapeutic agents, including antioxidants, anti-inflammatory drugs and saliva substitutes, to the oral cavity (and maybe even systemically) of BN patients should be considered. ${ }^{[26]}$ Thus, a specific mechanism may be responsible for the disturbed salivary and taste profile in EDs patients. Further studies may investigate this relationship.

The salivary acquired pellicle is a protein-based layer that may protect against erosion by acting as a diffusion barrier or a permselective membrane preventing direct contact between the acids and the tooth surface, ${ }^{[27]}$ thus reducing the dissolution rate of hydroxylapatite. ${ }^{[28]}$ The proteolytic activity of oral fluids contributes considerably to the formation and progression of dental erosion, probably by both the degradation of the demineralized organic structures of dentine and the weakening of the protective effects of the pellicle. ${ }^{[8]}$ Saliva of bulimic patients with erosion yielded higher proteolytic activity than that of the other two groups and collagenase activity was found to be enhanced in the group of bulimia patients with dental erosion. ${ }^{[8]}$

Emotional eating is a relevant psychopathologic dimension that deserves a careful investigation in both anorectic and bulimic patients. ${ }^{[29]}$ The reduction in salivary flow may also be related to side-effects of drugs, especially, those used for underlying depressive conditions. ${ }^{[30]}$ Additional factors such as fluid imbalance caused by overuse of diuretics and laxatives taken to prevent weight gain and by persistent vomiting, may be contributory. Several investigators reported reduced rates of unstimulated salivary flow in patients who binge eat or induce vomiting, however, no reductions in stimulated salivary rates were observed. ${ }^{[31]}$

Further, clinical research is recommended to improve our knowledge on the diagnosis and treatment of dental erosion in EDs patients among future health professionals, with a focus on prevention and awareness.

\section{CONCLUSION}

Patients with EDs may be at risk of developing erosive lesions on their teeth and the dental wear were major severity in the molars teeth. The clinical parameters are relevant to identify on the individual level the differences of dental wear in patients with EDs.

\section{REFERENCES}

1. Smink FR, van Hoeken D, Hoek HW. Epidemiology of eating disorders: Incidence, prevalence and mortality rates. Curr Psychiatry Rep 2012;14:406-14.

2. Hague AL. Eating disorders: Screening in the dental office. J Am Dent Assoc 2010;141:675-8.

3. Hoek HW. Incidence, prevalence and mortality of anorexia nervosa and other eating disorders. Curr Opin Psychiatry 2006;19:389-94.

4. Lo Russo L, Campisi G, Di Fede O, Di Liberto C, Panzarella V, Lo Muzio L. Oral manifestations of eating disorders: A critical review. Oral Dis 2008;14:479-84.

5. Buczkowska-Radlińska J, Kaczmarek W, Tyszler Ł, Mikołajczyk E, Fraczak B. Dental status in patients with eating disorders. Ann Acad Med Stetin 2007;53:90-3.

6. Mascolo M, Trent S, Colwell C, Mehler PS. What the emergency department needs to know when caring for your patients with eating disorders. Int J Eat Disord 2012;45:977-81.

7. Rytömaa I, Järvinen V, Kanerva R, Heinonen OP. Bulimia and tooth erosion. Acta Odontol Scand 1998;56:36-40.

8. Schlueter N, Ganss C, Pötschke S, Klimek J, Hannig C. Enzyme activities in the oral fluids of patients suffering from bulimia: A controlled clinical trial. Caries Res 2012;46:130-9.

9. Altshuler BD. Eating disorder patients. Recognition and intervention. J Dent Hyg 1990;64:119-25.

10. Dynesen AW, Bardow A, Petersson B, Nielsen LR, Nauntofte B. Salivary changes and dental erosion in bulimia nervosa. Oral Surg Oral Med Oral Pathol Oral Radiol Endod 2008;106:696-707.

11. Milosevic A, Dawson LJ. Salivary factors in vomiting bulimics with and without pathological tooth wear. Caries Res 1996;30:361-6.

12. Scheutzel P. Etiology of dental erosion - Intrinsic factors. Eur J Oral Sci 1996;104:178-90.

13. Moynihan P, Petersen PE. Diet nutrition and the prevention of dental diseases. Public Health Nutr 2004;7:201-26.

14. Curtis DA, Jayanetti J, Chu R, Staninec M. Decision-making in the management of the patient with dental erosion. J Calif Dent Assoc 2011;39:259-65.

15. Spitzer RL, Williams JB, Gibbon M, First MB. The structured clinical interview for DSM-III-R (SCID). I: History, rationale, and description. Arch Gen Psychiatry 1992;49:624-9.

16. de Carvalho Sales-Peres SH, Goya S, de Araújo JJ, Sales-Peres A, Lauris JR, Buzalaf MA. Prevalence of dental wear among 12-year-old Brazilian adolescents using a modification of the tooth wear index. Public Health 2008;122:942-8.

17. Landis JR, Koch GG. An application of hierarchical kappa-type statistics in the assessment of majority agreement among multiple observers. Biometrics 1977;33:363-74.

18. WHO. Oral Health Surverys: Basic Methods. Geneva: $4^{\text {th }}$ Edition; 1997

19. Lee WC, Eakle WS. Possible role of tensile stress in the etiology of cervical erosive lesions of teeth. J Prosthet Dent 1984;52:374-80.

20. Smith BG, Knight JK. A comparison of patterns of tooth wear with aetiological factors. Br Dent J 1984;157:16-9. 
21. El Aidi H, Bronkhorst EM, Truin GJ. A longitudinal study of tooth erosion in adolescents. J Dent Res 2008;87:731-5.

22. Ganss C, Klimek J, Lussi A. Accuracy and consistency of the visual diagnosis of exposed dentine on worn occlusal/incisal surfaces. Caries Res 2006;40:208-12.

23. Bassiouny MA. Clinical features and differential diagnosis of erosion lesions: Systemic etiologies. Gen Dent 2010;58:244-55;256.

24. Jaeggi T, Lussi A. Prevalence, incidence and distribution of erosion. Monogr Oral Sci 2006;20:44-65.

25. DeBate RD, Tedesco LA, Kerschbaum WE. Knowledge of oral and physical manifestations of anorexia and bulimia nervosa among dentists and dental hygienists. J Dent Educ 2005;69:346-54.

26. Blazer T, Latzer $Y$, Nagler RM. Salivary and gustatory alterations among bulimia nervosa patients. Eur J Clin Nutr 2008;62:916-22.

27. Hannig M. Ultrastructural investigation of pellicle morphogenesis at two different intraoral sites during a $24-\mathrm{h}$ period. Clin Oral Investig 1999;3:88-95.

28. Lendenmann U, Grogan J, Oppenheim FG. Saliva and dental pellicle - A review. Adv Dent Res 2000;14:22-8.
29. Ricca V, Castellini G, Fioravanti G, Lo Sauro C, Rotella F, Ravaldi C, et al. Emotional eating in anorexia nervosa and bulimia nervosa. Compr Psychiatry 2012;53:245-51.

30. Scully C, Bagan JV. Adverse drug reactions in the orofacial region. Crit Rev Oral Biol Med 2004;15:221-39.

31. Tylenda CA, Roberts MW, Elin RJ, Li SH, Altemus M. Bulimia nervosa. Its effect on salivary chemistry. J Am Dent Assoc $1991 ; 122: 37-41$.

\begin{tabular}{|l|l|}
\hline \multicolumn{2}{|c|}{ Access this article online } \\
\hline Quick Response Code: & \\
\hline & Website: \\
\hline
\end{tabular}

